\title{
Sibling Relationship during Middle Adulthood Years: A Qualitative Analysis
}

\section{Madhur Katoch* and Raj Pathania}

Department of Human Development and Family Studies, College of Community Science, CSKHPKV, Palampur, India

*Corresponding author: madhur.katoch@gmail.com (ORCID ID: 0000-0003-0087-6574)

Received: 21-02-2021

Revised: $24-05-2021$

Accepted: 11-06-2021

\begin{abstract}
The present investigation was an attempt to study the qualitative and in depth relationship among siblings of middle age through case study method. A representative sample of 20 middle-aged adults between the age of 40-60 years were selected from Udaipur city of Rajasthan state of India. These 20 respondents were selected from the main sample of 240 on the basis of all the five typologies i.e. Intimate, Congenial, Loyal, Apathetic and Hostile generated from Adult Sibling Relationship Scale. The results reveled that Loyal and Apathetic type of relationship between brother-brother dyad are guided by societal expectations, parental favoritism and property dispute that affected the relationship. Life transitions leads to congenial relationship among brother-sister dyad. Sistersister dyad reported intimate relationship resulting out of emotional closeness. Sister-brother dyad showed hostility because of the discrimination and parental favoritism faced by sister during her childhood years. Results also highlighted that middle aged adults do confide in or share their matters with their sibling,but the sharing is mostly superficial.
\end{abstract}

\section{HIGHLIGHTS}

(- Life transitions and various factors shape the nature and dynamics of sibling relations during adult years

o Contact among siblings during middle years is guided by obligations rather than through discretion.

- Adult middle aged have a sense of emotional security, comfort and psychological wellbeing by having a sibling in their life.

(- Property inheritance, envy or long time resentments leads to disputes or conflicts

Keywords: Middle age, sibling relationship, transition, contact, emotional closeness, confiding, conflict

Relationship is a pattern of intermittent interactions between two people involving interchanges over an extended period of time (Hinde, 1979). A person flourishes within a network of relationship with parents, grandparents, friends and with siblings. Siblings are the indispensable members of kin in fostering an individual's development. Growing up with or without sibling is likely to frame an individual's life experiences in varying brackets. Relationship between brothers and sisters is arguably the most enduring of human relationships, lasting most of the lifetime. The long duration of the sibling tie means that siblings are likely to bear common witness to more of the transitions made across the life course than other family ties. An individual spends 4050 years with one's parents, but life with siblings can last 60-80 years (Bank \& Kahn, 1997). A key aspect of sibling

How to cite this article: Katoch, M. and Pathania, R. (2021). Sibling Relationship during Middle Adulthood Years: A Qualitative Analysis. Int. J. Soc. Sci., 10(02): 181-186.

Source of Support: None; Conflict of Interest: None (c) 9 
relationships is the dynamic ways siblings use their resources to support each other at different points in each other's lives. Research on sibling relationship has seen a surge over the past few years. This acceleration is due to the reason that individualization nowadays is making people lonely and frustrated because of increased job demands, poor intimate relationships, fast paced life and technology dependence. The real essence of life is wasted in the complexities of life. Our old social support systems need to be revived where siblings fall in the inner circles of network. Various developmental researchers highlight the integral role played by multiple members of person's social network including parents and grandparents (Day \& Lamb, 2004; Lamb, 1986). Similarly, the role of siblings in the life of a person is also of most importance because of shared social capital and researchers are now gaining access to this area of study.

\section{Dynamics of sibling relationship during adulthood}

The relationship is bound by sharing and confiding among siblings (Katoch et al. 2009) especially in childhood years. However, dynamics in sibling relationship begins to appear when siblings enter adulthood years when roles and their lives orient towards their partners and children as they establish independence from parents and siblings. It is because of various life transitions like marriage, job demands, increase in geographic proximity birth of child etc. Therefore, the busy daily life of adults places some limitations on the ability to spend time with siblings. As adults enter middle adulthood, typically ages 40 to 60 they become actively involved with his or her family of procreation and economic endeavors.

Yet in old age, after children are launched from their parents' home, siblings have increased contact and greater intimacy (Connidis, 1992; Bedford, 1998). Various festivals like Rakshabandhan in North and Nagarpanchami in south of India that maintain the solidarity among the lives of siblings. Siblings are typically viewed as potential source of support, a type of "insurance policy" in later life (Hochschild, 1973).

Siblings because of their significance in the life of individual represent an untapped source of support and psychological well-being. Recent studies have highlighted a significant increase in older adult loneliness (Boger and Huxhold, 2018). This lack of support may be driven by increasing life expectancy, high divorce rate, and low birth rate experienced in the last several decades. Hence, clinically attempting to repair and strengthen sibling dynamics in adulthood may offer older adults a desperately needed source of support (Weisner, 1982).

Hence, middle adulthood years are important and crucial juncture where adults should reestablish their ties with their siblings and invest more in the nurturance of sibling relationship. Therefore, an understanding of sibling relationship that is present in middle years shall behelpful in well-being of families. Keeping in view these considerations the study was planned with the objective to qualitatively study the types of sibling relationship during middle adulthood years that fulfilled different psychological and social needs: Intimate, Congenial, Loyal, Apathetic, and Hostile. Therefore, the knowledge and insights yielded by this qualitative research could prove instructive in effort to promote and maintain the crucial support system that binds siblings throughout the life cycle.

\section{Methodology}

(a) Locale of the study: The traditional ethos governing adult sibling relationships are witnessing a change especially in contemporary urban areas. Therefore, the study was carried out in the urban areas who fall within the municipal limits of Udaipur city of Rajasthan.

(b) Sample: The sample for the present investigation comprised of 20 married middle aged adults (40-60 years) belonging to Hindu nuclear families of Udaipur city of Rajasthan state of India.. These 20 respondents were selected from the main sample 240 on the basis of all the five typologies generated from Adult Sibling Relationship Scale. The scale was standardized and its reliability is 0.92 and Intrinsic validity is $96 \%$. Five types of adult sibling relations i.e. Intimate, Congenial, Loyal, Apathetic and Hostile were generated from the scores obtained, based on type of contact, feelings of security, comfort and closeness and concern, type of confiding, envy, resentment, competition and avoidance.

Thus, five Male with Brother i.e. (Brother-Brother dyad) 
and five with Sister i.e. (Brother-Sister dyad) from a sample size of 120 males were selected. Similarly, from 120 female respondents, five Female with Sister i.e. (Sister-Sister dyad) and five Female with Brother i.e. (Sister-Brother dyad) form each typology were identified to develop case studies.

(c) Case study Proforma: Identified subjects were contacted personally at their respective homes for data collection. These were the subjects who were administered ASRS for quantitative analysis. Permission from these subjects was taken to collect information. As each case was subjected to an elaborate interview, therefore 5-6 visits per subject were made. The selected subject was required to respond to the semi-structured interview schedule. It probed into the reason of high or low contact, feeling of closeness towards sibling, type and degree of confiding and reasons for conflict with sibling.

(d) Data Analysis: The responses obtained on each aspect were subjected to detailed qualitative assessment. The details of each of the case study were double checked for accuracy. Researcher reviewed each case study carefully and highlighted specific themes that emanated from the content of the interview. Once an initial theme categorization of all the case studies was established, the second researcher completed an additional categorization of all cases.

\section{RESULTS AND DISCUSSION}

\section{Impact of gender, geographic proximity and contact patterns on sibling relationship}

In many case studies it was apparent that brother have moderate to low contact pattern with their siblings. They contact their siblings to know the wellbeing of their aging parents. The contact is obligatory in nature. The relationship among brothers is guided by societal expectations where they maintain the relationship out of duty. $\mathrm{Mr}$ ' $\mathrm{V}$ ' and his brother call each other once in a while, when there is something important to discuss or tell. He says that he calls his brother generally to know their father's health or general wellbeing of his and family. They talk once in a week and the mode of contact is phone call. According to him nowadays no one has spare time to just go around and visit their sibling unless there is some important event or family gathering, where they are expected to go. Unlike old days when sibling visits each other and stay with each other for days and weeks after their marriages. But now the scenario has changed because of increasing urbanization and privatization, where people are working too hard for their ends to meet. However, he stated that family gatherings or events like festivals are enough to meet their sibling. Another case of Mr J where he had Apathetic type of relationship with his brother. They have low or almost negligible contact pattern. He called his mother who lives with his sibling, once in a while to know her well-being but never talked to his brother.

On the other hand, sisters have very close relationship with their sibling especially sister. Mrs " $C$ " says she remains in frequent contact with her sister. She talks to her twice a week. Whereas only sisters found to have hostile relationship with their brothers. Mrs A claimed she don't have any contact with her brother since last 10 years or so neither personally nor by phone. Her only contact with her family of origin is with her mother, whom she called once in a while. She claimed that her brother was never interested in her life, even her parents were more attached to him since childhood. She added that he was privileged being a male member and had been given better opportunities in every aspect i.e. education, care, clothes or love. Mrs 'B' 49 yrs old had two years' younger sister with whom she maintain regular phone calls once in two weeks or so, yet they live in the same city they visit each other personally once a week. Very few siblings of middle age had discretionary contact with siblings. Overall the general contact pattern between siblings is through phone and they meet their siblings regularly if they reside nearby. The contact of males and females with their sibling remain almost same.

\section{Emotional closeness, feeling of security and comfort provided by siblings}

When subjects were asked about feelings of emotional closeness with their siblings most of them responded by having a feeling of security with their siblings. 
According to Mr. ' $\mathrm{V}$ ' their busy schedule lessens their visits a great deal. Even he visits his brother frequently, yet he finds comfort in knowing that if he were to need anything at all, there would be his brother always to help him. On the other hand, $\mathrm{Mr}$ ' $\mathrm{N}$ ' added that his relationship with his sister was good during childhood but as she got married they became closer, because of their little age difference and her friendly relations with his wife. It enhanced their relationship; he says that as we age we share common experiences of getting old and experiences of being a parent. On the other hand Mrs. 'A' viewed her relationship with her sister as not very close, though she has a feeling of concern and felt bondage with her. Many subjects also reported to have instrumental support from their siblings. Mrs. ' $\mathrm{C}$ ' eyes lit up every time she talks about her kin. She further stated that she is very much close and emotionally dependent on her, more than anyone else. Her sister is like a sound board for her. She always feels relaxed after talking to her.

Mr K on the other hand never felt emotionally close to his sister because she never understands anyone's problems and what she cares about is her family.

\section{Level of Confiding between siblings}

Confiding among siblings is from general talks to superficial sharing and sharing of inner most feelings. Conversations among siblings generally revolve around asking about each other's well being to asking about their aging parent's health. Brothers have reported that their talks are about each other's well being. Mr. ' $\mathrm{N}$ ' have a close relationship with his sister but he added that if he face any problem he would like to discuss it with his spouse first, with whom he is very much closer. He says that he like to talk out his problems with his wife first rather than his sister, according to him... you can't always burden your sibling with your own problems, because she has her own family to look after, her own involvements or commitments or problems then why to burden her with his own. Similarly, Mrs. 'A' voiced that she talks to her sister weekly but it is nothing personal, we happen to talk about recipes, what things we purchase, where we had gone for holiday outings etc. I prefer to talk out my problems or feelings to my spouse. She felt closer to her husband than her sister or her friends.

\section{Conflict among siblings}

Various life transitions have changed the relationship. Some factors are parental favoritism that created sibling rivalry, socio-economic differences, conflicts related to property, feelings of resentments etc. The major reason of conflict among siblings was property disputes. Mr. 'J' confessed that after their father's death two years ago, he had a major dispute over property inheritance with his brother. He felt cheated and even their mother didn't say anything on the matter, as according to $\mathrm{Mr}$. ' $\mathrm{J}$ ' she is living with his elder brother and is more attached to him. Another subject Mrs.' M' added that she was not even asked for the share in her father's property as she was in need of money that time for her daughter's marriage. Moreover, when she asked her mother for the share she made her ashamed by saying that they had spent enough money on marriage by giving her dowry. She noted that this discrimination made her resent her brother. She also felt that her brother was the favored child in the family and she faced discrimination from the very beginning.

In some cases, various life events and transitions revealed negativity in the sibling dynamic.

\section{Factors affecting the siblings' relationship}

During the interview they were asked how the relationship has changed over the years. Many subjects felt that the factor that acts as a barrier for contact among siblings is the geographic distance. $\mathrm{Mr}^{\prime} \mathrm{J}^{\prime}$ stated that distance between his siblings and other responsibilities make them aloof. I prefer my nearby friends and my spouse to share my feelings. Going through similar experiences like getting married, having families and moving out of the house tended to make siblings fall apart. Mrs. 'C' stated, ...my job is so demanding and looking after my in laws and children keeps me so busy that there is no time to talk to my siblings. I feel closer to my children than my siblings.

$\mathrm{Mr}^{\prime} \mathrm{N}^{\prime}$ told that his sibling express little interest in his life and seems to be caught up in her own lives. Whenever I talk to her she rants about her children, or in laws never 
asks about what going on in my life...so it's easy to listen to her rather that sharing your life, he added laughing.

\section{DISCUSSION}

The themes emerging from this qualitative assessment highlight the diversity of life experiences and transitions that happen throughout the life span of an individual. It is a complex web of factors, causative or life transitional that shape the nature of sibling relationships. It is influenced by various factors and life transitions like gender, marital status, parental status, geographic distance, changes in living standard, caring for aging parents, empty nest, genetic closeness, parental favoritism and many others, as emerged from qualitative data and leads to varied types of adult sibling relations. First, variations in the sibling bond based on gender, contact pattern and geography proximity are commonly found in studies on sibling relationships across the lifespan. Gender does not account for the difference in contact. It may account to the reason that both males and females during middle adulthood years perform same developmental tasks, like maintaining an economic standard of living or assisting or guiding teenagers in becoming responsible adults. Their preoccupations or other involvements left them at almost same platform. Therefore, the contact of males and females with their sibling remain almost same.

It can be analysed from the results that for majority of subject's contact with their siblings occur primarily on various family events like marriages, religious occasions, child birth, and festivals like Rakhi, Bhai Dooj, Diwali or death of any family member. Ross and Miligram (1982) postulated that one of the main functions of family rituals and ceremonies is to emphasize and renew the feeling of their solidarity, for they are outward symbols of unity. Kinship contacts probably last longer in these areas, then in any other, for they are the main way of publically demonstrating family identity.

The next factor which may act as a barrier for contact among siblings is the geographic distance. In similar findings Eriksen and Gerstel (2000) suggested that the most consistent predictor for contact is distance, a potent determinant of all forms of kin contact and feeling of closeness.
The emphasis on having emotional closeness, feeling of security from siblings can be understood in the context of other studies. According to Cicirelli (1995) relationship with siblings could contribute to higher life satisfaction, higher morale, fewer depressive symptoms, psychological well-being and a greater sense of emotional security during later years of life. Regarding the sharing of their feelings subjects reported to prefer their spouses over their siblings. According to Cicirelli (1989) siblings who considered themselves compatible and report being emotionally close are still less likely to share intimate personal life details or consult their sibling while making important family decisions. Analysis of results highlight that middle aged adults do confide in or share their matters with their sibling. But the sharing is mostly .

Negativity in relationships is due to many factors like property inheritance, envy or resentment.

\section{CONCLUSION}

Results from the current study call attention to various intricacies of sibling relationship that are based on gender, geographic distances. The feature depicting contact pattern or emotional closeness or confiding among siblings are all found to be distinct and are affected by various life transitions and other factors. It all shaped the dynamics of this relationship. The change is apparent in human life, similarly the dynamics in sibling relationship is also seen. The interaction of other dyadic relationship also affects the nature of this relationship. Interdisciplinary significance can also be studied to clarify the nature of sibling relationship throughout entire life span.

\section{REFERENCES}

Akiyama, H., Elliott, K. and Antonucci, T.C. 1996. Same sex and cross sex relationships. Journal of Gerontology: Social Science, $\mathbf{5 1}$ : 374-382.

Bank, D.P. and Kahn, M.D. 1997. The sibling bond. Basic Books, New York, pp. 171-78.

Bedford, V.H. 1998. Relationships between adult siblings. In: The diversity of human relationships. Auhagan, A. and Von, M. S. (Eds.). Cambridge University Press, New York, pp. 120-140. 
Boger, A. and Huxhold, O. 2018. Do the antecedents and consequences of loneliness change from middle adulthood into old age? Developmental Psychology, 54 (1): 181-197.

Cicirelli, V.G. 1989. Feeling of attachment to siblings and well being in later life. Psychology and Aging, 4: 211-216.

Cicirelli, V.G. 1995. Sibling relationship over the life span. Plenum Press, New York, pp. 202-209.

Connidis, I.A. 1992. Life transitions and the adult sibling ties. Journal of Marriage and the Family, 54: 972-982.

Day, R. and Lamb, M. 2004. Conceptualizing and measuring father involvement: Pathways, problems and progress. In: R. Day \& M. Lamb (Eds.), Conceptualizing and measuring father involvement (pp. 1-15). Hillsdale, New Jersey: Lawrence Erlbaum Associates.

Eriksen, S. and Gerstel, N. 2002. A labour of love or labour itself: care work among adult brothers and sisters. Journal of Family Issues, 23: 836-856.
Hochschild, A.R. 1973. The unexpected community. University of California Press, Berkeley, CA, pp. 67-70

Katoch, M., Sharma, S. and Chopra, G. 2009. Perception of confiding among siblings during middle adulthood years. Himachal Journal of Agricultural Research, 35(1): 89-92.

Weisner, T.S. 1982. Sibling interdependence and child caretaking: A cross cultural view. In: M.E. Lamb \& B. Sutton-Smith (Eds.), Sibling relationships: Their nature and significance across the lifespan (pp. 305-327). Hillsdale, NJ: Lawrence Erlbaum Associates.

White, L. 2001. Sibling relationship over the life course: A panel analysis. Journal of Marriage and the Family, 63: 555-568. 